General paper

\title{
PREDICTION OF FAILURE IN ROCK MASSES BY ACOUSTIC EMISSION
}

\author{
Kazutoshi Michiniro*, Koji Hata**, Toshio FujIwara** and Hisaya YoshiokA** \\ *Department of Civil Engineering, Setsunan University, \\ Ikeda-nakamati, Neyagawa, Osaka 572, Japan \\ **TechnicalResearch Institute, Obayashi Corporation, \\ Shimokiyoto, Kiyose, Tokyo 204, Japan
}

\begin{abstract}
When constructing large caverns such as the one used for an underground powerhouse, it is of extreme importance to assure the stability of the cavern. As one of the techniques for stability monitoring, uniaxial compression tests were performed in various rocks and acoustic emission(AE) activity was measured. From the examinations of AE activity and the maximum amplitude of a single event, two types of AE occurrence patterns and three types of $m$-value variations were found. When predicting failure modes by means of AE, it is thought that the total $\mathrm{AE}$ counts and the $m$-value can be useful for non-homogeneous rocks. On rocks of schistose or very homogeneous structures, the total AE counts provide useful information on failure prediction but the $m$-value does not. Furthermore, from the results of spectral analysis of AE signal waves measured, it is found that the dominant frequency increases with increasing load.
\end{abstract}

Key words: Acoustic emission, m-value, Frequency analysis, Prediction of failure, Stability of cavern, Rock masses

\section{INTRODUCTION}

It is extremely important to evaluate the properties of rock masses when an underground opening is executed, e.g., tunnel excavation, underground powerhouse etc. However, it is extremely difficult to predict the occurrence of sudden failure due to rock burst, or to evaluate the unstable zone in a rock mass. Traditionally, the failure of rock during tunnel excavation or in mining area was predicted by observing the rock noise. When stress of rock mass exceeds the equilibrium state toward failure, the stored-up energy is released. A part of this released energy could be released as elastic waves which are known as acoustic emission (AE). In recent years, $\mathrm{AE}$ property of rock mass or soil mass has been studied in the field of civil engineering, such as in predicting stability of the slope [1] and performance of the concrete structure [2] etc.

Mogi [3] pioneered AE research in Japan. In his research, he studied failure of brittle rocks by $\mathrm{AE}$ signals, through which he tried to clarify the mechanism of earthquakes. Boyce et al.[4] carried out uniaxial compression tests on various types of rocks to evaluate various $\mathrm{AE}$ parameters, and also compared their finding to those obtained by Mogi [3]. Michihiro et al.[5] studied eight different types of rock and their $\mathrm{AE}$ characteristics. They confirmed the dependence of the AE characteristic on the rock type. In this paper, the prediction of the failure of rock mass is attempted based on the AE pattern. $\mathrm{AE}$ signals were monitored when the rock samples were subjected to the uniaxial compression tests. Special attention was given to $\mathrm{AE}$ counts.

\section{EQUIPMENT AND EXPERIMENT}

Figure 1 shows the experimental set-up and the block diagram for the experiment is shown in Fig.2. The system is capable of measuring the axial load, axial strain, $\mathrm{AE}$ count and the maximum $\mathrm{AE}$ amplitude of $\mathrm{AE}$ signal, etc. The axial load was measured with the load cell mounted inside the upper loading plate, while the axial strain was measured by attaching the strain gauges on the surface of the rock sample. AE measurement was conducted using two types of transducer (1) a resonant type; and (2) a non-resonant type (broad-band). Both transducers were of PZT type (Porcelain of zirconiumtitanium). Their responses are shown in Fig.3. It is important for analyzing the signal wave to take into account the transducer's response. To remove the effect of the transducer's response, it is desirable to keep the transducer's response at the base level, but in practice it is rather complicated. In the present study, to remove or to minimize the effect of transducer's frequency interaction with the $\mathrm{AE}$ signals in the rock samples during loading, a non resonant type of transducer was used and the measurement was done basically in the range of $100 \mathrm{kHz}$ $\sim 1 \mathrm{MHz}$ (Fig.3(b)). Measurements were made at $5 \mu \mathrm{s}$ sampling rate (Nyquist frequency was $1 \mathrm{MHz}$ ).

It is important to remove the noise while measuring the $\mathrm{AE}$ counts accordingly to remove the noise generated 


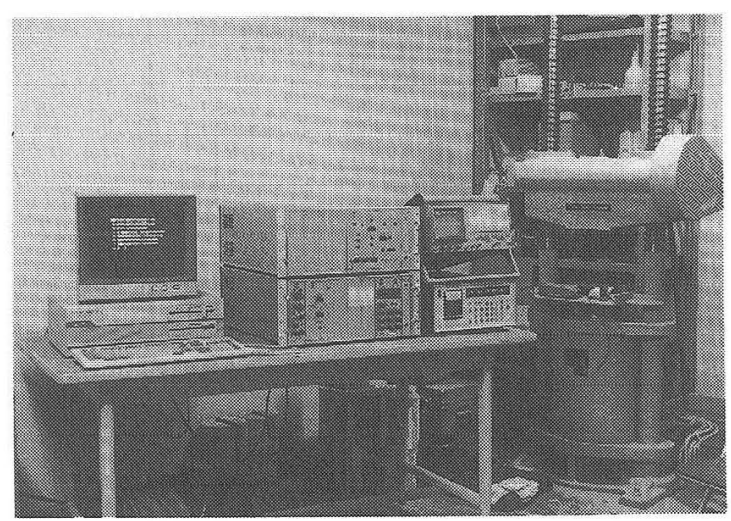

Fig.1. AE measuring system.

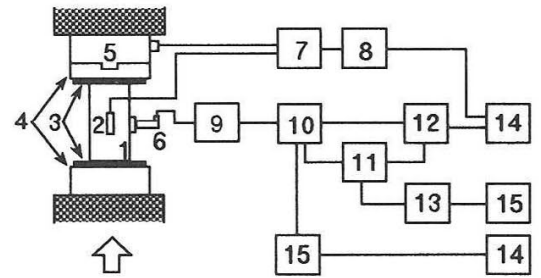

\begin{tabular}{ll} 
1.Specimen & \multicolumn{1}{c}{ 8.Digital data recorder } \\
2.Strain gage & 9.Pre-amplifier \\
3.Sponge pad & 10.Discriminator \\
4.Loading plate & 11.Amplitude detector \\
5.Load cell & 12.Counter \\
6. Transducer & 13.Distribution analyzer \\
7.Strain meter & 14.Personal computer \\
& 15.Digital storage scope
\end{tabular}

Fig.2. AE measuring block diagram.

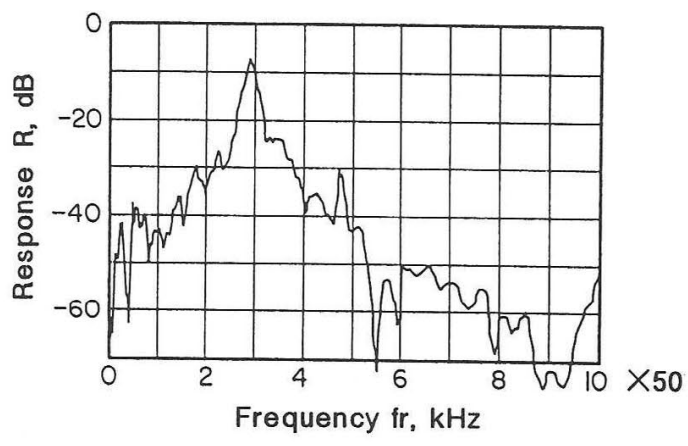

(a) fr: $140 \mathrm{kHz}$.

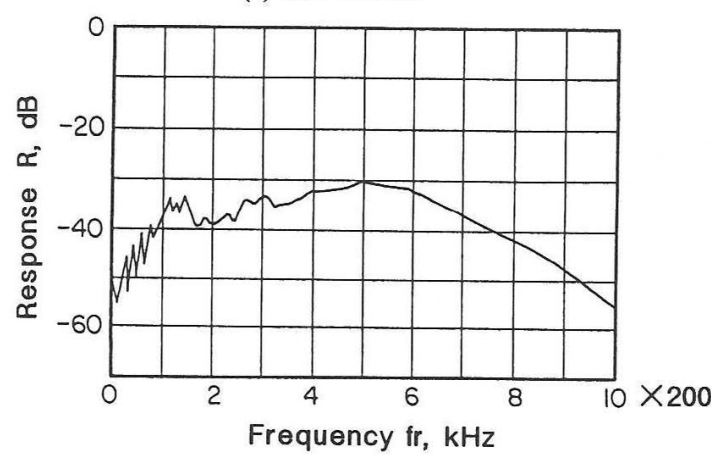

(b) fr: flat $(140 \mathrm{kHz}$ to $1 \mathrm{MHz})$.

Fig.3. Spectral responses.
Table 1. Identification, mean uniaxial compressive strength $(\sigma \mathrm{c})$, mean unit weight $(\gamma)$ and number of samples.

\begin{tabular}{l|l|r|r|r}
\hline \multirow{2}{*}{ Identification } & \multirow{2}{*}{ Location } & \multicolumn{2}{|c|}{ Mean values } & Number \\
\cline { 3 - 5 } & $\begin{array}{c}\gamma, \\
\mathrm{kN} / \mathrm{m}^{3}\end{array}$ & $\begin{array}{r}\sigma_{\mathrm{c}}, \\
\mathrm{MPa}\end{array}$ & $\begin{array}{c}\text { of } \\
\text { samples }\end{array}$ \\
\hline Granite & Inada & 25.8 & 131.7 & 30 \\
\hline Granite-porphyry & Akikawa & 26.3 & 82.9 & 12 \\
\hline Rhyrolite & Minakami & 26.4 & 119.1 & 8 \\
\hline Sand-stone & Aiki & 25.9 & 210.3 & 25 \\
\hline Tuff & Dojo & 24.3 & 83.6 & 15 \\
\hline Clay-slate & Uji & 26.9 & 94.6 & 9 \\
\hline Crystal-schist & Fujioka & 28.9 & 71.2 & 11 \\
\hline Marble & Italy & 26.5 & 74.0 & 12 \\
\hline Mudstone & Machida & 18.3 & 4.1 & 7 \\
\hline
\end{tabular}

due to the interaction between the sample surface and the loading plates, sponge pads of $7 \mathrm{~mm}$ thickness was used. The rock types used in the current study were selected from igneous, sedimentary as well as from metamorphic rocks.

Table 1 shows the physical properties, provenance and the number of samples used in the current study. Cylindrical specimens were prepared with the diameter of $30 \mathrm{~mm}$ and the length more than twice the diameter. A loading rate of $250 \mathrm{kPa} / \mathrm{s}$ was maintained and the $\mathrm{AE}$ count was measured till the failure.

\section{EXPERIMENTAL RESULTS AND DISCUSSION}

In the following paragraphs the obtained results are presented and are discussed.

\subsection{Acoustic Emission Count and Amplitude Distribution}

In general, the rock failure happens when the energy exceeds the critical level. From the beginning of the formation of the micro-crack till the rock reaches the failure state, the AE count increases accelaratedly. By observing $\mathrm{AE}$ behavior closely we could predict the rock failure. Also by observing the amplitude of the $\mathrm{AE}$ count, it may be possible to predict the failure.

Isimoto and Iida [6] studied the naturally occurring earthquakes in an underground laboratory (set-up) by observing the micro fluctuation in the horizontally placed instruments. Their results can be expressed in the following form:

$$
n(A)=k A^{-m}
$$


where $A$ is the maximum amplitude, $n(A)$ is the incremental number of earthquakes, of which amplitudes are between $A$ and $A+d A$. $m$ and $k$ are the empirical constants. In the above equation, the constant $m$ defines the relation between the number of earthquakes and the maximum amplitude of the wave on a logarithmic scale, which is nearly a straight line. In Japan, the value of $m$ varies from $1.5 \sim 2.0$. For the tremors caused by the volcanic action the constant $m$ is usually greater than 2 . In 1949 Gutenberg and Richter [7] proposed the following relation:

$$
\log N=a-b M
$$

where $N$ is the total number of earthquakes, $M$ is the magnitude and $a$ and $b$ are the constants.

Because magnitude $M$ is $\log A$ and $b=m-1$, Eqs. (1) and (2) are identical. The difference is that Eq. (1) defines the wave amplitude and Eq. (2) defines the magnitude.

Since the equations are based on naturally occurring earthquakes, the applicability to the very small samples tested in the laboratory is of concern. Iio [8] and Kusunose et al. [9] have confirmed through their research. Authors have applied Eq. (1) to interpret experimental results. Figures 4 through 8 and Figs. 10 through 13 show the relations between axial strain and $m$-value and total AE count for different samples.

Figures 4, 5, and 6 show typical results obtained on the granite, granite-porphyry and rhyolite, respectively. In all the cases, at the strain ratio of $0.7 \sim 0.8$ to the maximum strain, the measured $\mathrm{AE}$ count increases rapidly or suddenly. This can be due to either the sudden increase in micro-crack or the large cracks coalescing each other. Correspondingly, the $m$-value decreases suddenly at about the same level of strain ratio where the $\mathrm{AE}$ count increases suddenly. As a point that $\mathrm{AE}$ cumulative count changes suddenly, the generation of large amplitude of the $\mathrm{AE}$ wave is suggested. If we pay close attention to the composition of the material used in the present study they are generally composed of mineral quartz, potash feldspar and some dark minerals, which results in the the generation of particular wave media for each material. In such heterogeneous material the development of crack or the propagation of crack near by the failure surface leads to sudden generation of the AE events. It is also noticed that with the increasing stress level the dominant frequency of the $\mathrm{AE}$ wave from increases. This phenomenon was also noticed by Mogi[3].

Figures 7 and 8 show the results obtained on the sandstone and tuff. As seen in the figure, the AE count does not increase as suddenly as in the case of the igneous rocks discussed in the preceding paragraph. The increase in $\mathrm{AE}$ count has various stages. In sandstone the $\mathrm{AE}$ count follows the process of "Closing of crack", " Linear elastic deformation", "Stable fracture propagation", and "Unstable fracture propagation" as proposed by Bieniawski [10] and is shown in Fig.9. On the otherhand, when we look at the behavior of $m$-value during failure, the $m$-value becomes very small at the

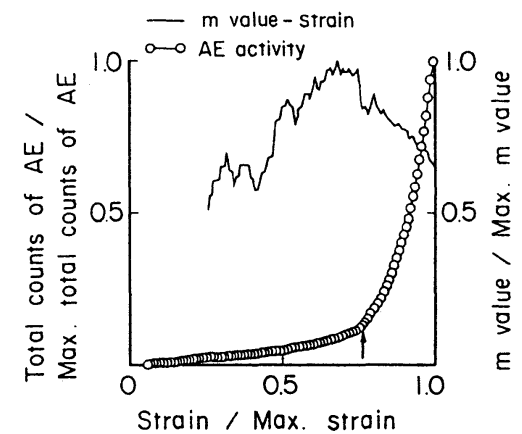

Fig.4. Relationship of axial strain versus $m$-value and AE activity in a granite specimen subjected to uniaxial compressive stress.

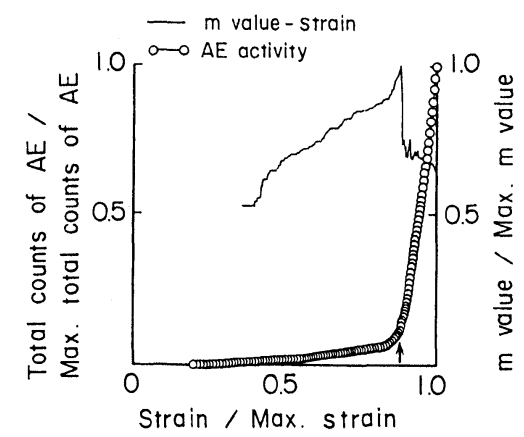

Fig.5. Relationship of axial strain versus $m$-value and AE activity in a granite-porphyry specimen subjected to uniaxial compressive stress.

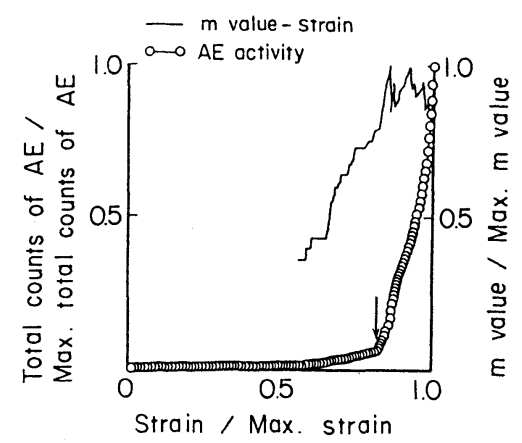

Fig.6. Relationship of axial strain versus $m$-value and AE activity in a rhyolite specimen subjected to uniaxial compressive stress.

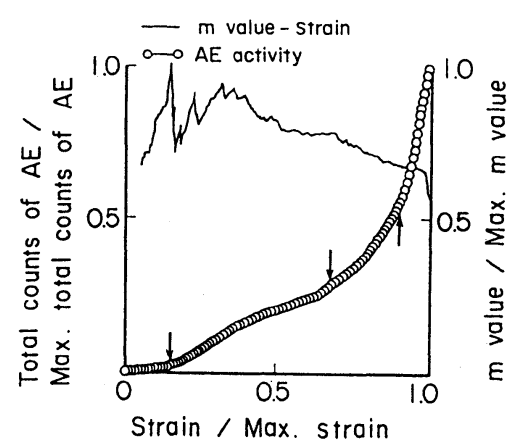

Fig.7. Relationship of axial strain versus $m$-value and AE activity in a sandstone specimen subjected to uniaxial compressive stress. 


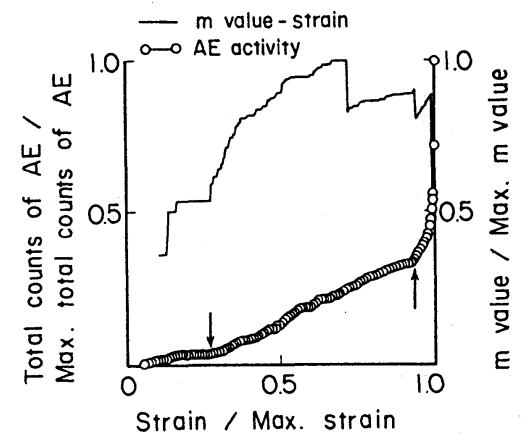

Fig.8. Relationship of axial strain versus $m$-value and $\mathrm{AE}$ activity in a tuff specimen subjected to uniaxial compressive stress.

final failure (which is $97 \%$ of the measured strain). Compared with granite, sandstone can be considered as very homogeneous. In this type of material, at the tip of the micro-crack, the generation of large amplitude of the $\mathrm{AE}$ wave is suggested.

Figures 10 through 13 show the typical results obtained in clay-slate, crystal-schist, marble, and mudstone, respectively. It shows the same trend about the $\mathrm{AE}$ count of such igneous rock as granite. However, when we look

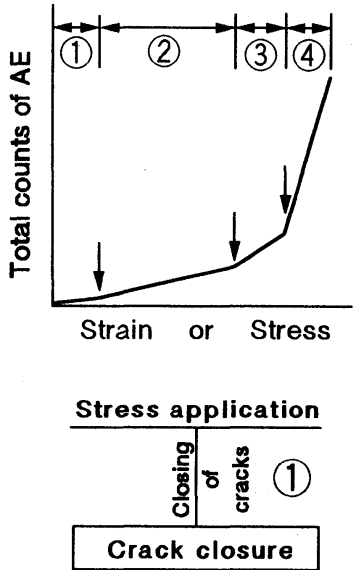

离语产

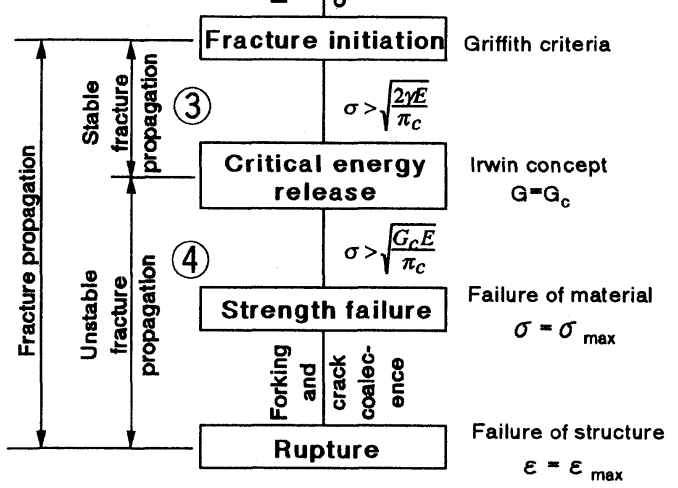

Fig.9. Comparison with Bieniawski's result.

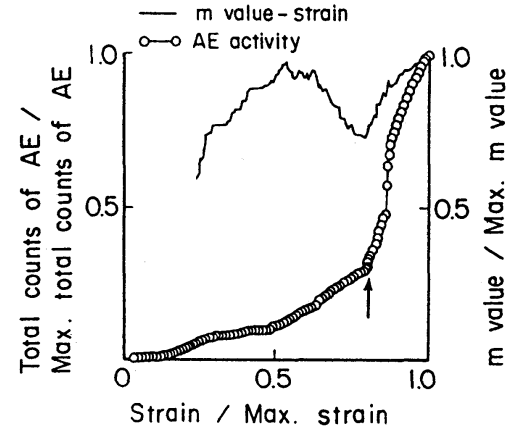

Fig.10. Relationship of axial strain versus $m$-value and $\mathrm{AE}$ activity in a clay-slate specimen subjected to uniaxial compressive stress.

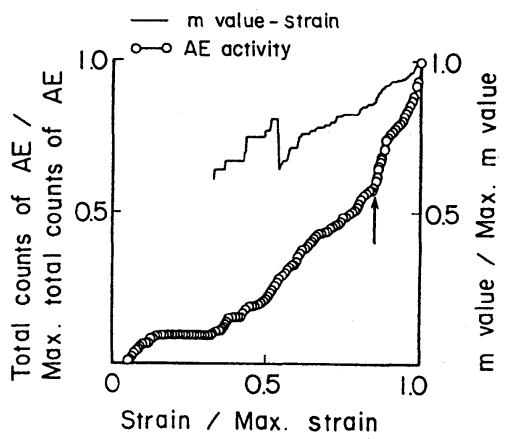

Fig.11. Relationship of axial strain versus $m$-value and AE activity in a crystal-schist specimen subjected to uniaxial compressive stress.

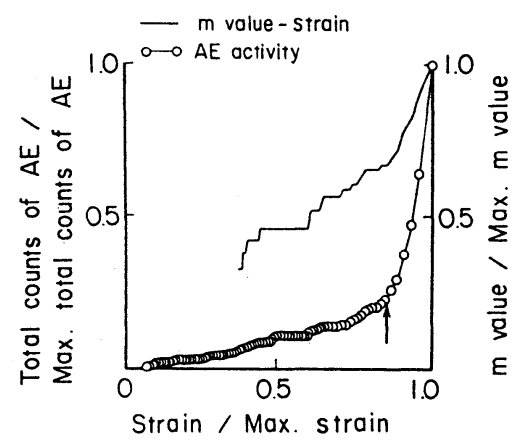

Fig.12. Relationship of axial strain versus $m$-value and $\mathrm{AE}$ activity in a marble specimen subjected to uniaxial compressive stress.

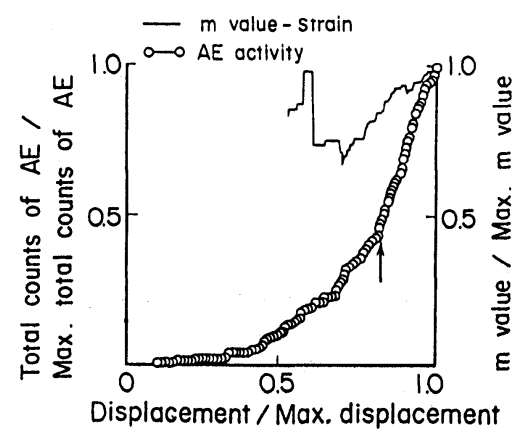

Fig.13. Relationship of axial strain versus $m$-value and AE activity in a mudstone specimen subjected to uniaxial compressive stress. 

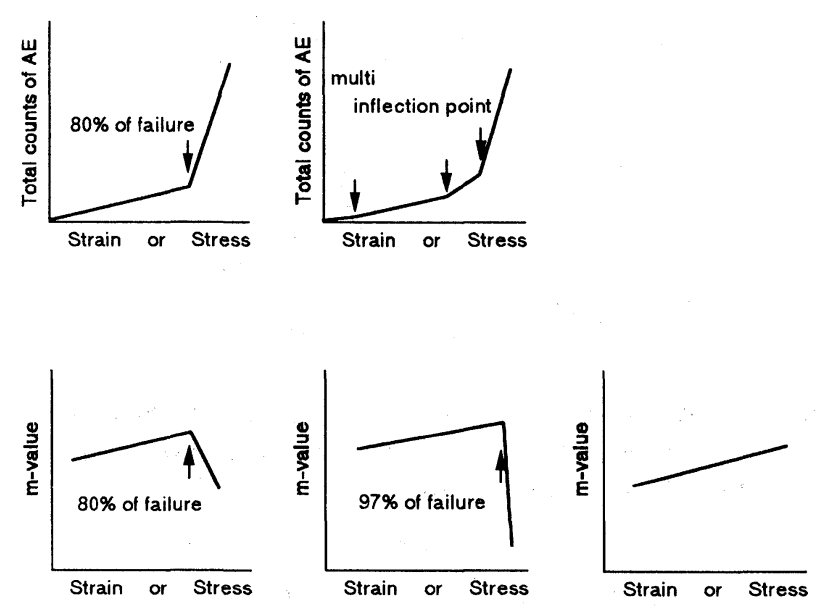

Fig.14. Classification of behaviors of AE activity and $m$-value.

at the $m$-value at the failure, $m$-value does not become as low as discussed above. Two reasons were considered for the lesser amplitude of AE observed. The first reason is that sliding failure might have been more predominant at the grain boundary than at the shistore. The second is that the marble and mudstone were too homogeneous for AE to generate. The test results were all similar except at some specimens with greater cracks on their surfaces. For such cases, the amplitude of $\mathrm{AE}$ was incredibly great shortly after loading so that the generating pattern was not clearly observed. Depending on the type of rock material, two types of $\mathrm{AE}$ generating behaviors and three types of $m$-value distribution are classified (Fig.14).

On the basis of the results above, it is possible to predict the failure and crack generation pattern from the measurement of $\mathrm{AE}$ occurrence and the amplitude. Though it is difficult to extrapolate the laboratory data to the rock mass in the field, the noticeable trend of these results in conjunction with the in-situ testing can be useful in predicting rock failure.

\subsection{Acoustic Emission Waveform and Frequency Analysis}

In itself $\mathrm{AE}$ signal contains lot of information, as discussed above. The AE occurrence and the maximum amplitude are such parameters. Chugh et al.[11] used three different samples subjected to uniaxial tension test and analyzed the result. They found the pre-dominant frequency of AE signal changes with the applied stress. Boyce et al.[4] tested rock specimen under uniaxial compression condition and reached the same conclusion as that of Chugh et al.[11]. On the basis of these results, it is possible to predict the failure in the rock mass.

Combined with the above discussion it is possible to make a better judgment in predicting rock failure. In following paragraphs, it is discussed that structural
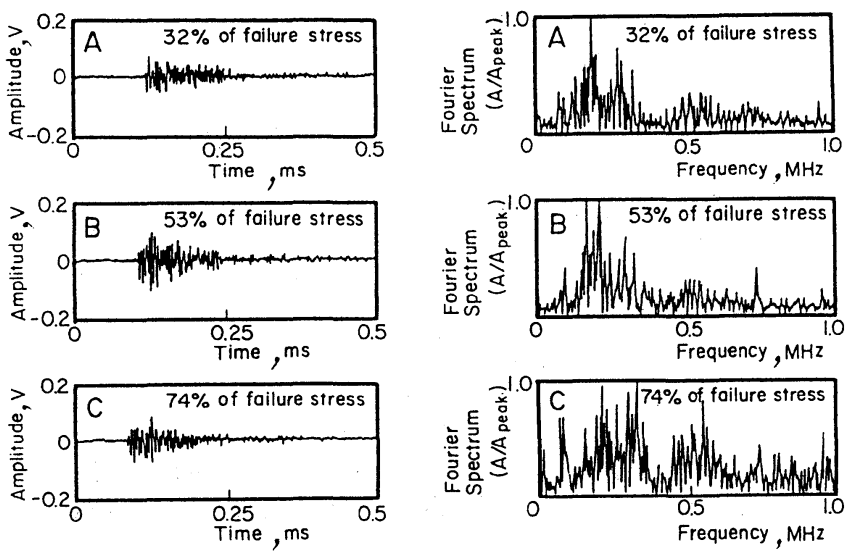

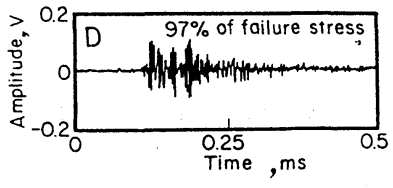

(a) Waveform.

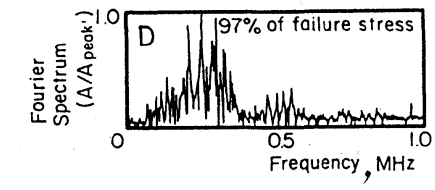

(b)Fourier spectrum.

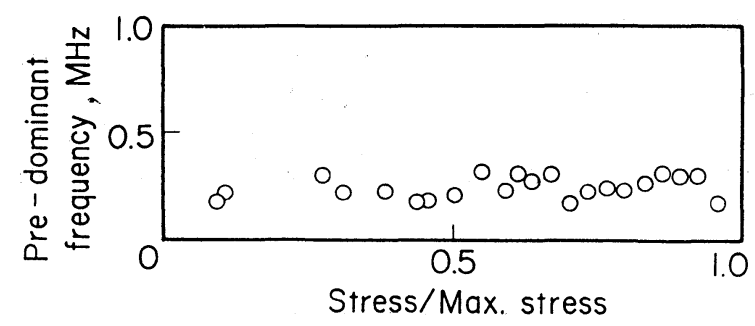

(c) Relationship between pre-dominant frequency and axial stress.

Fig.15. AE waveform in granite specimen.

change leads to the changes in the characteristics of $\mathrm{AE}$ waveforms. Thus, $\mathrm{AE}$ signals were recorded and analyzed.

Two types of rocks were selected (granite as a heterogeneous material and sandstone as homogeneous material) in the experiment. Figures 15 and 16 show the experimental results on granite and sandstone, respectively. Figures 15(a) and 16(a) show the observed $\mathrm{AE}$ waveforms of granite and sandstone, respectively. It can be said that the general trend shows two patterns of (1) burst type; and (2) continuous type. The burst type waveform represents the micro cracking formation whereas the continuous type represents the plastic deformation. In both rocks, the AE waveforms show very short stand-up. The usual periods from generation of the wave to the decay were about $0.3 \mathrm{~ms}$. However, waveforms of $1.0 \mathrm{~ms}$ were recorded near final failure. It is clarified that of at moderate level of stresses the $\mathrm{AE}$ generation is burst type whereas at the higher stresses, the $\mathrm{AE}$ is of the burst types overlapping with the continuous type with higher frequencies. If only the shape of $\mathrm{AE}$ waveforms are considered, then there is hardly any difference in the behavior of sandstone and granite.

Even if the degree of heterogeneity is taken into 

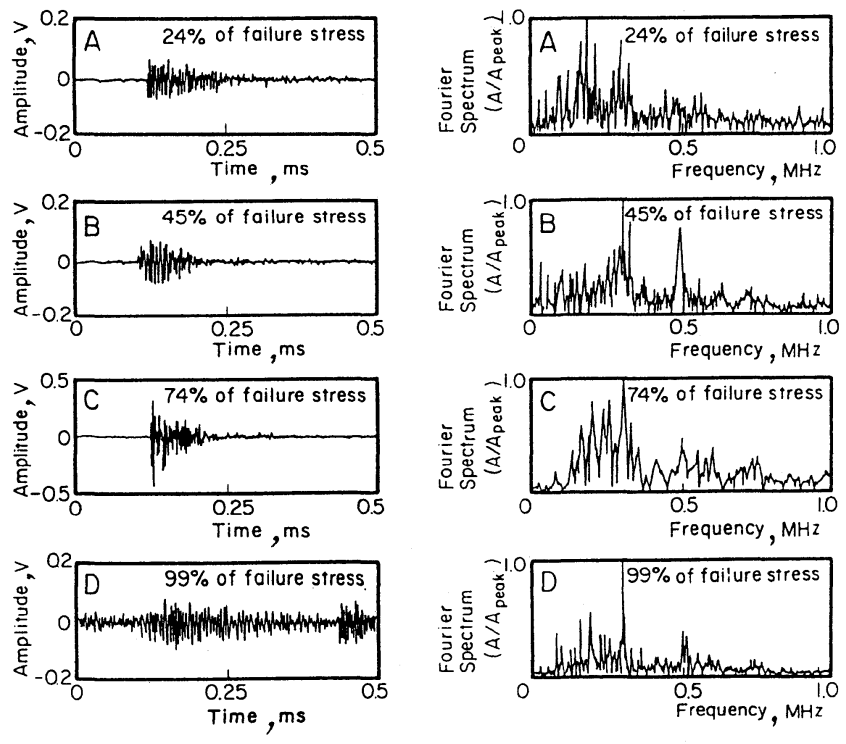

(a) Waveform.

(b)Fourier spectrum.

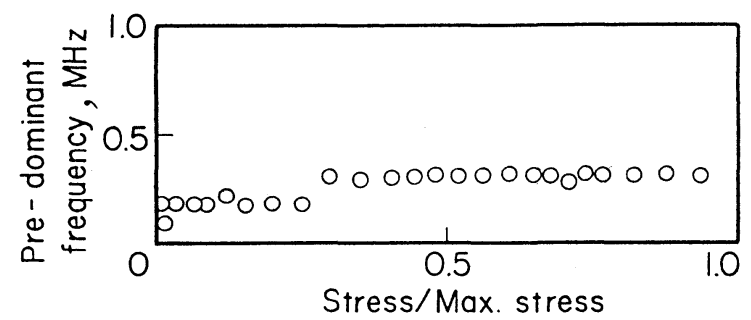

(c) Relationship between pre-dominant frequency and axial stress.

Fig.16. AE waveform in sand-stone specimen.

consideration, not much difference can be seen. Figures 15 (b) and 16(b) show the results of frequency analysis from observed $\mathrm{AE}$ signal waves. In both rocks, at low stresses the peak is clear whereas for higher stresses the peak is not very well recognized. Figures 15(c) and 16(c) show the relation between pre-dominant frequency and the axial stress. Though there seems to be some scattering, the pre-dominant frequency increases with the increasing axial stresses. In sandstone we can observe the difference in pre-dominant frequency beyond $20 \sim 30 \%$ axial stress. This trend of pre-dominant frequency depends on the rock type. It could be available for predicting rock failure.

A simple frequency analysis was carried out for both the rock samples, special attention was given to the predominant frequency. From the used samples it is difficult to have any qualitative result. However, it can be understood from the above going discussion that the rock type/genesis plays an important role in defining the predominant frequency range of the rock. In the present analysis, the characteristics of the transducer was not taken into consideration. This problem remains in future research.

\section{CONCLUSIONS}

Nine different rock samples were used in the present study to elucidate the relationship among $\mathrm{AE}$ count $\sim m$ value axial strain, and two samples were used to establish the relationship between pre-dominant frequency and the axial strain. Following conclusions can be drawn:

(1) In igneous rocks, the $\mathrm{AE}$ count and $m$-value changes suddenly and this sudden change occurs approximately at $80 \%$ of the failure stress.

(2) In sedimentary rocks, the AE count changes at various levels of applied stress. The $m$-value decreases suddenly which approximately at $97 \%$ level.

(3) In metamorphic rocks, especially very homogeneous rocks, the $m$-value increases with the applied stress. AE count also increase with the applied stress but changes suddenly at about $80 \%$ of the failure stress. Further, $m$ value compared with those igneous rocks are different.

From the above going discussion it is clear that the $\mathrm{AE}$ generation varies with the genesis of rock. The AE count and $m$-value can be used to predict rock failure. In very homogeneous rocks $\mathrm{AE}$ count can be used to predict the rock failure but not the $m$-value. Frequency analysis was carried out, it is clear that the pre-dominant frequency changes as propagation of rock failure. The frequency analysis is available for predicting rock failure.

\section{REFERENCES}

1.A.Chichibu, K.Jo, M.Nakamura, T.Goto and M.Kamata, J. Acoustic Emission, 8, No.4 (1985) 65.

2.M.Ohtsu and Y.Sakata, 1987 Nat. Conf. Acoustic Emission, Japan, Fukuoka (1987) 54 (in Japanese).

3.K.Mogi, Bull. Earthquake Res. Inst., 40 (1962) 125.

4.G.M.Boyce, W.M.McCabe and R.M.Koerner, Acoustic Emissions in Geotechnical Eng. Practice, STP750 (1981) 142.

5.K. Michihiro, K. Hata, T.Fujiwara and Hisaya Yoshioka, Proc. 20th Symp. Rock Mech., Japan, Tokyo (1981) 71 (in Japanese).

6.M.Isimoto and K. Iida, Bull. Earthquake Res. Inst., 17 (1939) 443 (in Japanese).

7.B.Gutenberg and C.F.Richter, Princeton Univ. Press (1949).

8.Y.Iio, J. Seismological Soc. Japan, 2, No.35 (1982) 183 (in Japanese).

9.N.Kusunose, O.Nisizawa, H.Ito, T.Ishida and I.Hasegawa, J. Seismological Soc. Japan, 2, No.34 (1981) 241 (in Japanese).

10.Z.T.Bieniawski, Eng. and Geo., 2, No.3 (1967) 149.

11.Y.P.Chugh, H.R.Hardy Jr. and R.Stefanko, Proc. 10th Symp. Rock Mech., America, Texas (1968) 73. 